\title{
VALUE PROBLEMS IN THE QUEST FOR SANCTION IN SOCIAL PLANNING
}

\author{
Thomas Dale Watts \\ Tulane University
}

\begin{abstract}
At all stages in the social planning operation values play a decisive role. Dahn's six value dilemmas confronting the planner are explored, with two added: planner values are often indistinguishable from the escape from controversy and are unwilling to reveal monopolistic and repressive atmospheres and situations in society. If Marcuse and the Frankfurt School are correct in characterizing society as repressive, then the obligation of the planner accelerates even more to the forefront - to represent the most liberating of values. Rein's three planning strategies are traced: rational analysis (knowledge power), citizen participation, and elite consensus, with the accompanying value difficulties of each.
\end{abstract}

\section{Introduction and Definition of Terms}

The purpose of this study is a consideration of value problems in the quest for sanction in social planning. Values are heavily laden throughout the entire process of social planning, perhaps more so than in any other field of social work endeavor (if only because more people are involved). The entire question of value in social planning is essentially a philosophical one, in that the term itself necessarily involves and connotes ultimate philosophic considerations such as beauty, truth and the good (Frankena, 1967:229). As soon as the planner begins his work he is already functioning with three major value espousers: 1) the elite institutions, 2) the consumer clients, and 3) himself. The last may be the most difficult of all, in that one's own values slither into play in the most inauspicious of ways, and often under the "cloak of neutrality" (Friedrichs, 1970:77-91).

What, then, do we mean by "value." Le Senne thought of value as eternal by reason of its origin but becoming temporal by reason of human conditions and initiative. Val ue was an "inexhaustible expansion" (Davenhaver, 1971:38-39). Williams (1965:401-403) notes that values are concerned with the ends or goals of action, and are consanguineous with the choice of means, conjointly affecting the sundry categories in which reality structuring takes place in the cognitive processes of the viewer. Values are: 1) touchstones or criteria for decisions on what should be wanted, and 2) conceptions of the desirable. They are general and directive principles of a noticeably high, abstract nature that serve as theoretical lighthouses for tangible patterns of behavior. Value, then, is any directive which proceeds from a higher norm(s) to the lower norms of an order (Kluckhohn, et.al., 1951:388-433). A preference within this framework would be a "value in action" (Kahn, 1969:98). Carzo and Yanouzas (1967:147) seem. to sum it up best when they reiterate that values "are the criteria or standards that guide 
individuals in their selections of the appropriate behavioral alternatives in a given situation."

What is meant precisely by the word "sanction"? By sanction we imply authorization or ratification. It most emphatically implies an authority that involves a relationship which obtains between: 1) the activities that are prescribed or permitted by the norm of which that sanction is a part, and 2) the stable, persistent expectations which individuals have in regard to wantgratification and want-deprivation (gratification and deprivation being viewed as opposite directions on a single psychological continuum) (Parsons, 1951:203). How much individuals or groups will deprive themselves and for how long is dependent on the amount of sanction or credence they will allow the planner. Sanction implies legitimacy, especially for those categories of city planning and social reform "that share a common ideological commitment to introduce social innovation - new programs and new ideas that will reduce or eliminate social problems" (Rein, 1969:233).

Lastly, what do we mean by the word "planning"? Perhaps a generic concept of planning could best be epitomized as "an ongoing process concerned with detailing the differences between a set of needs and the resources available to meet these needs" (Kaitz and Hyman, 1970:159). This definition could apply equally well to both social and physical planning, as could many other concepts discussed in this essay. But our focus will be on social planning, which Robert Morris describes as "a relatively systematic method which men use to solve social problems" (Morris and Binstock, 1966:5). Essential to this planning process is, obviously, the planner. It is to him that sanction is garnered, assumed, or granted. It is his responsibility to determine the dimensions and the possibilities of this sanction, and necessarily, its component, inevitable limitations.

\section{The Importance of Values in Social Planning}

At any and all stages in the planning operation values play a decisive, crucial, allimportant role (Kahn, 1969:99). For if it is true that policy comes before planning, then we can assuredly state that "a value is logically prior to the policy which carries it into effect" (Simey, 1968:66). Perhaps the social theorist and profound observer of the American social scene, Gunnar Myrdal, made the most erudite observations concerning values:

That a term is value-loaded is, even when used in scientific inquiry, not of itself a ground for objection. It has been a misguided endeavour in social science for a little more than a century to seek to make 'objective' our main valueloaded concepts by giving them a 'purely scientific' definition, supposedly free from any association with political valuations. . . . The re is no way of studying social reality other than from the viewpoint of human ideals. A 'disinterested social science' has never existed and, for logical reasons, cannot exist. The value connotation of our main concepts represents our interest in a matter, gives direction to our thoughts and significance to our inferences. It poses the questions without which there are no answers (Mrydal, 1958:1).

Since consciousness is manifested "indubitably" in man in a most singular and unique way (Teilhard de Chardin, 1961:83), and is at the same time, as R. D. Laing (1965:113) words it, a "type of radar, a scanning mechanism," one can easily join with Rollo May (1967:150) in saying that man's capacity for value-making, "like freedom, reason and the other unique 
characteristics of the human being - is based upon his consciousness of himself." Hence, any fully conscious man is possessed of a seemingly endless range and variety of values, ranging far and wide over his perceptual and experiential landscape. Erik Erikson (1960:46), reflecting on the weighty role that values play in forging one's own personal identity, remarked that values, inner resources, and opportunities for action coincide with one another to help create identity.

The noted philosopher Nicholas Rescher (1967:130-137) has written that there is a remarkably close kinship between the ascriptions of values and traits of character. Value explanations, then, are naturally akin in their logical structure to character explanations, because a subscription to a certain value is one of the most important elements definitive of a man's character. For example, the deeply-held values of a Martin Luther King or a Gandhi were strongly indicative of their respective characters. One does not need to plumb the depths of Freud to realize and comprehend this fundamental connection. One observer goes so far as to proclaim that character adjustment in the various stages of personality growth and development is virtually synonymous with a "process of living up to a set of values" (Ginsburg, 1950:478).

Of course, there are many different and varying kinds of values, and it is important for the planner to begin to distinguish between them, weigh groups of values against others and the priorities that some values receive over others. The Jesuit analyzer of the casework relationship, Felix Biestek (1957:95), has separated basic, vital values (such as legal conformance, morality) at one end of the lamina and relatively unimportant valuations at the other end (like housekeeping standards, etc.) with a plethora of shades and degrees in between. Suffice it to say that in the Biestek classification basic, vital values can be so powerful that men will literally die in order that they might be maintained. It is particularly these kinds of values that should enlist the ultimate planner concern, because they are truly "inescapable elements of any rational decisionmaking process or of any exercise of choice" (Davidoff and Reiner, 1962:111).

In recent years, values have been seen as inestimably salient in the framing and in the structuring of scientific investigations. Sociology, especially, has been in the forefront, with the likes of the perspicacious Alvin Goulder (1968:103-116), and Robert Friedrichs (1972) exposing the myth of a value-free and neutral sociology or social science. They argue, quite persuasively, that all social scientists, whether they be a Parsons, a Chomsky, or a C. Wright Mills, approach the study of society from a certain value-base, a certain set of assumptions and presuppositions (of which they are often unaware or only partially aware). We now see a call for putting the social scientist's values face-up on the table, a call for diminution and de-emphasizing of the "priestly" Parson-Etzioni-Lipset mold in favor of the "prophetic" caste of Mills. This new sociological emphasis on value (and on "prophetic" style) should not go unheeded by the planner. Judging from the labors of planning theorists of the likes of Morris, Rein, Kahn and Davidoff, value prominence will not stand quiescent.

\section{Value Problems as Dilemmas for the Planner}

"Man is full of wants," said Pascal (p. 18), "he loves only those who can satisfy them all." The planner is faced with the age-old dilemma of not being able to "satisfy all the people all the time." He faces a myrid range of competing values, from a seemingly endless variety of groups, agencies, organizations, with a sanction given to coordinate and effect these values that is often shaky at best. Unlike his counterpart in socialist countries (Fisher, 1962:251), he remains always cognizant of his frequently subliminial status. Kahn assays that the planner is 
faced with the following value problems:

a. There are conflicting, competing values at stake.

b. Value questions must often be posed in an 'as if' form.

c. Difficulty of clarifying just what the prevelent values or preferences are.

d. Values are not always transitive.

e. Disputes often rage as to whose choices are relevant or most relevant to the decisions to be made.

f. Difficulty in translating technical issues into their approximate value consequences in a completely objective and understandable, perceivable fashion (Kahn, 1969:106).

The contravening values existent in any community are obviously of prime moment to the concerned planner. Community leaders "tend to think of social welfare programs in, to use Galbraith's term, 'their own conventional wisdom'. " The leaders have a widely shared understanding of how they believe social welfare ought to operate. Frequently, though, their view is completely at variance with the desires and needs of those who are clients of social welfare agencies (Burke, 1965:268). Perhaps this is the most common form of value opposition: provisioner and provisioned, institutions and their consumers. Morris (1966:191) observes that the lack of technical preparedness to construct adequate barometers of need "is shown in recent studies of the gross differences in perception that separate professional staff, agencies, and consumers, and thus affect utilization patterns." Just as Marx speaks of class conflict as being positioned at the very crux of societal interaction, so too, Litwak and Hylton (1962:395-420) speak of conflicting values and the need for independence as being the raison d' etre in the very origins of the agency or organization.

Planners often must perforce phrase questions in an "as if" format. What consequences that might ensue from the construction of a maximum security institution in a given community becomes, as it were, a "loaded question" for both planner and community. Other "as if" questions (which are necessarily futuristically-oriented) would or could concern economic opportunities, or race relations, or adequate public assistance. Often, health and welfare planning agencies have been forced to avoid such questions and as a result the project involved "none of the crucial and legitimately controversial issues on the community agenda . . but . . . instead (was) an antiseptic undertaking widely accepted as 'worthwhile'" (Adrian, 1960:4). In the "as if" dimension the planner is attempting to imagine and to convey all relevant, conceivable experiences that could potentially be drawn on in the planning process.

It is indeed difficult for the planner at times to adequately discern and clarify just what the prevalent values or preferences are. Within even one individual's value scheme one finds stances in favor of integrated schools, but against busing, in favor of more social programs, but against higher taxes. Frequently, a kind of immobilization takes place, and the more stronglyheld values of some begin to fill the vacuum. The value problems that emerge from a situation of value immobilization become acute indeed. Here the planner must be especially alert to the 
complexities and contingencies and the state of obfuscation surrounding the whole matter.

Another thorny element that seems to be continually erupting centers around the changing nature of values. Perhaps because of the recent work of Alvin Toffler (1970) and others, in addition to the seemingly near-panic preoccupation with change in various social science studies, one would be lead to believe that all values are in constant flux, with only a modicum of permanence and stability. But a closer examination reveals that there are some values that are less transitive than others and are perhaps considerably less transitive than many planners care to believe. Raymond Plant (1970:2) has observed: "When can the individual justifiably refuse to accept the claims made upon him by society, by the roles which he has to play?" The answer to this is that he can never really do so, but that there are certain basic and relatively unchanging values connected with the essence of man that reside, sometimes quite uncomfortably, alongside those values that are intertwined in the existence of men. In short, does existence precede essence or essence precede existence?

The planner faces the problem of whose choices are relevant or most relevant to the decisions to be made. In other words, how does one choose the "relevant" community in exploring preferences? In urban renewal, for example, should decisions be effected employing the values and preferences of the residents of the immediate area, the downtown civic clubs, or what? MacRae (1965:255-260) notes that hardly anyone questions the need for planning but that the essential questions are: "Who should do the planning?" or, more urgently, "Why haven't you been planning to avoid the mess we are in?" Actually, planning may have been going on all along but at the expense of some choices being considered more "relevant" than others. In the course of urban renewal, it appeared that the values of one "relevant" community were chosen over the values of other sundry communities holding other values.

Problems often coalesce over the difficulty in translating technical issues into their value consequences in a completely objectivistic trajectory. How does the planner handle the desires and objectives of a multi-service agency wishing to include abortion counselling in their service program in a strongly Orthodox Jewish or Catholic neighborhood? Howard remarks about how many societies "take pride in how effectively their cultures inculcate values, but are unconcerned about the erratic way in which 'the good things of life' become available" (Howard, 1969:29). If this be true, then certainly manuvering specific technical issues back to their inevitable valueunderpinnings cannot be an easy task.

In addition to the six value problem areas that Kahn enumerates, I must add two of my own: first, the values of the planner intermesh so subtly with the societal brew that he stirs that it is virtually impossible at times for him to distinguish. "Appropriate planning action cannot be prescribed from a position of value neutrality," agrues Davidoff (1965:331), "for prescriptions are based on desired objectives." If it is true, as Maclver (1965:5) says, that "the values and standards of a people inevitably are related to the conditions they have experienced, "then this holds equal truth and validity for the individual - for the planner.

The planner is a product of his experience, and that experience is necessarily puny and limited alongside the collected individual experiences of all those for whom he must plan. Perhaps the sagacious advice of Henry Maas (1958:22) to caseworkers may be equally utilizable for the planners: ". . . help the client to see as clearly as possible and to modify apparently obstructing attitudes, feelings, and objective realities in his problem situation. "If the planner 
realizes that he does possess values of his own, and that they are not entities to be completely avoided (or denied), then he has already taken an important first step in the overall effectiveness of his planning activity.

The second value problem that should concern the planner is his 1) natural-born tendency to create an agreement as an escape from controversy, and 2) unwillingness to reveal and to explicate monopolistic and repressive situations existing in society, which tend to thwart and even extinguish the preferences and values of many. Robert Morris, in expressing some of the hindrances that conspire to diminish any effectiveness in change agents, noted:

1. The commitment, inculcated by professional social work training, to education and the creation of a consensus to a controversy as the major acceptable strategy for prof essional behavior....

2. The preoccupation with professional integrity. ...

3. A latent, if not manifest, commitment on the part of social work toward protecting the employing agencies... (Morris, 1969:283-284).

The Frankfurt School neo-Marxist philosopher Herbert Marcuse has painted a philosophical picture of a society essentially characterized by domination and repression - a "repressive tolerance." "What Marcuse likes to call liberalist society, is based, "Maurice Cranston (1969:39) remarks, on a form of domination so subtle "that the majority accept and even will their servitude. In such a condition tolerance as traditionally understood serves the cause of domination. "If Marcuse is philosophically correct then the obligation of the planner accelerates even more to the forefront - for he must strain to provoke and to stimulate, to formalize and to represent, to elucidate and to express, all those values that tend towards enfranchising, liberating, rejuvenating, and restoring men.

\section{Three Strategies: Rational Analysis, Citizen Participation, Elite Consensus}

In Martin Rein's conceptualization there are three essential strategies, all replete with multi-variant value bases, that contribute to at least partial resolution of the problem of sanction in the social planning process: "They are elite consensus, rational analysis, and citizen participation. Each strategy is crucial. None is sufficient by itself, for each has inherent limitations, but the efforts to pursue more than one strategy at a time often lead to conflict and contradiction. Thus in the effort to resolve one dilemma another is created (Rein, 1970:200). In this section attention will be focused on the value dimension composite of each strategy, something that Rein does not sufficiently explore. Indeed, the value dimensions of each strategy assume wide import, for if it is a truism that strategy is directly related to "the dimensions of feasibility in a given situation," (Morris and Binstock, 1966:151) then certainly those elements of feasibility, or possibility, are intertwined with the values and attitudes of those to whom the question of feasibility or possibility is put.

The first procedure or strategy giving justification, or sanction for intervention is that of elite consensus. By this approach the planner has his activity endorsed and supported by the elite or ruling leadership of the major institutions and controlling interests in the community. The semina! problem here that the planner immediately confronts is that often the organization 
"can never rise sufficiently above identification with their own organization to furnish the active, vigorous leadership needed ..." (Mayo, 1941:158). Nevertheless, the planner is transacting with concentrated power, and, as Coughlin observes, "Community planning will . . . be impotent if it has no access to community power. This means that it must involve itself with the power institutions that exist in the community. The objectives. . . will not be achieved without using power and authority as instruments; without this our mark will be neither significant nor enduring" (Coughlin, 1961:39).

Thus through this strategy the planner is quite concerned with the power that organizations have and can muster. Organizations and organizational leaders can be very effective indeed in giving "weight to the findings and recommendations" (Manser, 1960:37). Our very lives are spent either in organizations or in contact with organizations in a multi-farious number of situations. So much of our lives center around organizations that philosopher John O'Neill (1972:10) states that "human experience and vision accumulates only in the circle of social relations and institutions, which enlarge and deepen the sense of our sentiments, deeds and works through the symbiosis of solidarity and personality."

Hence institutions protect their own interests and mobilize their considerable resources to maintain themselves. Planners often find that negotiating with these realities tends to ultimately compromise their own values in subservience to the values of the institutions with whom they work. The further and the deeper a planner proceeds along this strategy pathway, the more difficult it becomes to convince himself that innovation and change are actually being effected. The facts are that the values of institutions are such that change comes very hard, and is not considered acceptable unless the environment is seen as demanding it. The planner, when he is employing a primarily institution-oriented strategy, must be fully cognizant of the why and wherefore of institutional and organizational values, or else face the inevitable consequences of resultant lack of effectiveness in convincing organizations of needed attitude and value change.

Another major strategy to be considered here is that of "rational analysis" or "power of knowledge"schema, the notch on the institutions-planner-consumer scale where the values of the planner are paramount. This strategy subsumes a "professional" approach - that is, the planner supposedly harbors a thorough and comprehensive knowledge and information base enabling him to effectively perform the planning operation.

Since knowledge is of such importance here it follows that the planner will wish to implement research. Aside from the fact of the possibility of the research (which is often lengthy) interfering with the urgency of a given planning operation, it poses rather vexing value dilemmas as well. One cannot get far away from value, no matter how "objective" the research, no matter how supposedly "value-free" the planning approach. For out of the research the planner is faced with selecting priorities amongst various choices.

Because of the nearly universalistic aspect of scarcity of resources in meeting the multitudinous variety of problem demands, the planner is inevitably faced with choosing priority problems and priority goals. Morris and Binstock say that ". . . it goes without saying that the preference goal is not the planner's ideal, ultimately perfect solution to the problem under consideration. He is not omnipotent. What he can accomplish is limited by his capacity for weilding influence. . . A preference goal, then, is neither a utopian scheme nor an affirmation of the status quo. It is a goal which embodies some estimate of feasibility" (Morris and Binstock, 
1966:27).

Samuel Mencher essays the following for quality priority planning:

1. The plan must include all welfare functions, even if the body using the plan will attend to some, rather than all, functions listed. Thus, functions normally public must be included in the priority-planning of a voluntary body even if, after the ordering of functions, public functions will be relegated to public responsibility.

2. The major values or goals desired in a community welfare program must be delineated before examination of specific functions or services that support these values. There are four major elements in the priority system: (a.) values or goals, (b.) causal factors or variables, (c.) professional functions, (d.) specific services. These must be treated as distinct factors. . . .

3. Once the units of the system have been set and the values selected, ordering of fuctions and the services relevant to these functions is a matter of expertise. ...

4. Services must be organized by some rational method according to the functions they serve. . .

5. . . . although the purpose of priority plans is to aid in the allocation of community funds, nowhere in current plans is there an attempt at conversion into budgetary decisions.... (Mencher, 1967:34-35).

Even without any noticeable amount of research, or without any stated and above-theboard priorities such as we have just considered, the planner is still dealing with his own personal preferences, his own attitudes and values, his own particularistic visionary stance. In some ways, especially for those with a positivistic or scientific-determinist bent, this is a reality that is often shirked (Simey, 1968:195). The two dimensions, the personal and the social, are closely intertwined. Just as Gouldner (1968:103-116) has exploded the myth of a value-free sociology, could we say that it is any less the case with the individual planner in the midst of the planning operation?

The third strategy is that of citizen participation, whereby the planner can claim sanction or legitimacy if the programs are supported and upheld by the recipients and consumers of the service. Certainly this ranks as the most widespread block that the planner must cope with, and to that extent, may be the most complex. Is he to be an "advocate" for the consumer, when Lisa R. Peattie (1968:87) suggests "that the weight of the evidence so far implies that the very considerable short-term inefficiencies and exasperations of advocacy are paid for by the pressure which they generate for a social policy more sensitive and adaptive to social reality?" Or is he to be a kind of "value technician," as some have proffered, merely effecting whatever values are placed on the table from whatever source? 
Certainly in this strategy the paramount interests of the planner relate to and are hinged on the values of the clients or consumers concerned. Perhaps the most astute perceptor of this intricate interaction is the planning theorist Paul Davidoff:

The planner should consider values from two perspectives: first, as the clients' internal states of valuation; second, externally, as the entities which are valued... To lend substance to our discussion of internal states, let us focus on values such as health, wealth, and power, which might be considered values at a middle range of generality. These values should be considered in the following ways.

1. For a given value: how widely is it held? What is its spread and distribution in the institution and among client groups?

2. What is the intensity of the value? Techniques of measurement are not sharply developed here. The only meaningful intensity scale may be one measuring overt behavior, for example, migration. It may also be desirable to distinguish between those values held in private and those shared as when attitudes are publicly voiced or voted. The planner might be particularly concerned with identifying conditions under which privately held values become public. This is related to whether a value is strongly held by an individual, or whether he is amenable to changing it.

3. Does the individual believe he can or cannot influence the achievement of a goal?

What are the characteristics of the external value entities? The stock of such things as wealth or health that an individual possesses at any time, in combination with his internal values, provides a significant basis for planning analysis. An individual's well-being is measured by:

a. his absolute stock of valued entities;

b. divergence of his stock from his own goals (his aspirations);

c. divergence of the stock of valued entities from a level set by others (this is the familiar notion of standards). (Davidoff and Reiner, 1962:109)

If the planner is truly interested in "a set of social services which are from the consumers" point of view and not always primarily from the service institutions' point of view, "(Rein, 1968:17) then he must isolate and assimilate the values held in as thorough a manner as Davidoff describes. One must pay particular heed to values that are covertly proprietored over those more overtly apparent. Sometimes duties are of such moment, (Newman, 1959:49) and indeed the daily, grinding humdrum of much of modern-day life of such moment that the expression in any fashion of one's true values and attitudes on given matters hardly occupies prime attention in the consciousness of many. Peter Marris (1962:186) remarks that in a highly integrated, populous society, "each man and woman is individually impotent, dependent upon anonymous millions to complete his work and satisfy his needs. He needs to be able to retreat into a less 
intimidating and complex world, when he can feel himself of more account. . . ." Indeed, the planner must be singularly adept at the subtle, pain-staking, ferreting-out process that is necessary in a society where man increasingly feels himself to be dehumanized, alienated and unneeded.

In all of this, many individual needs and values can come together to make a farily viable and consistent whole. This whole we can speak of succinctly as the public interest, commonly accepted objectives and goals shared by the larger community. Alan Altshuler, a perceptive planning critic, states:

Every political planner, no matter how specialized, must be guided by some conception of the public interest. Since plans are proposals of concerted action to achieve goals, each must express his conception as a goal or series of goals for his community. He will probably conceive these goals as constantly shifting rather than highly stable, as always intermediate rather than final, and as more in the nature of criteria than of concrete destinations. Community goal conceptions are likely to have these characteristics because of the limitations on collective human foresight and imagination. Nonetheless, it is impossible to plan without some sense of community goals, call them what you will ... (Altshuler, 1965:186).

The planner participates as knowledgeably as he is capable in the heady, oft-times frustrating, and complicated enterprise of determining just what is the exact composition and nature of the public interest. What he perceives as the public interest may only be an illusory figment of his imagination. There are many "publics" making up the "body public." Here, the value exigencies of the second strategy concerning the individual planner and his values, comes directly into play. Really, citizenry strategy cannot be fully separated from planner strategy, for ultimately the very perception of the public interest with its accompanying enunciation and explication usually rests in the perceptual and cognitive processes of the planner himself. This should in no significant manner hinder an earnest, intense effort on the part of the planner himself in the direction of as impartial, objective and forthright a consideration as could be fashioned of the manifold and intricate values, needs and aspirations of an often dissimilar, diverse and highly elusive "body politic."

\section{Conclusion}

The urban community is a complex, variated system of interrelated, juxtaposed elements, and, according to Davidoff, "relatively little is known about how the elements do, will, or should interrelate. The type of knowledge required by the new comprehensive city planner demands that the planning profession be comprised of groups of men versed in contemporary philosophy, social work, law, the social sciences and civic design . . ." (Davidoff, 1962:337). Truly, a virtual Rennaissance, da Vincian type of man is called for to meet the desperate, disordered, intricate organism that we know of as the urban environment today. Interestingly, social planners reside at the discomforting, but at the same time potentially enervative and creative point where the social sciences and philosophy meet and are brought to bear on substantive problems (Emmet, 1967:21). Perhaps social planning could best be thought of as an explorative "field laboratory" for the effective byplay and mutual nourishment that can occur in the steady process of applying these disciplines to practical social problems. 
"Order, " said Pope (1950:302), "is Heaven's first law." It surely is true then that men are possessed of a desire for harmony, for order, for planning. Planning is a necessary and inevitable prefix to harmony and order. "An unplanned society - if, indeed, such a vagary were possible in the real world - would be an unf ree society," states Walter Firey (1965:48), "An unplanned society would be devoid of the norms which prescribe what ought to be or has a right to be at any future time. . .." This "ought to be" aspect is, we must remind ourselves, an ideal.

Hans Kelsen observes that the plan "is a normative order rather than a natural order. Indeed such attributes of planned activities as value, for instance, have their being entirely in the propositions of a normative order" (Kelsen, 1959:229). In all of this, values are an inevitable and requisite ingredient of any intelligible planning activity. Values can often unwittingly "obscrue the use of knowledge" (Lappin, 1967:57) in that certain puissant groups with strongly held values can use (and abuse) knowledge to their own ends. Or, as Bergson (1939:223) averred: "In a general way, reality is ordered exactly to the degree in which it satisfies our thought."

In further consideration of the three Rein-formulated planning strategies investigated here, what commonly-held environmental and societal values are the most conducive in provising of a climate for effective planning? The Robert C. Fried study of planning in post-war Rome tends to suggest the inherent limitations, rather than the potentialities, of neutrality and expertise as resources. Fried states that resources would seem to be most valuable and the strategy of professionalism to have the greatest chances of success (for city planners, at least) where:

1) public attitudes are supportive; 2 ) politicians feel relatively secure; 3 ) the national government takes most of the responsibility for planning; 4) civic improvement associations are strong; 5) there is a strong upper class, oriented toward civic improvement; 6) the community has an achievement oriented ethos; 7) the community has a high status; 8 ) there is some degree of consensus and mutual trust among and within the parties; 9) there is a strong Socialist party; 10) the legitimacy of political neutrality is recognized in such institutions as civil service, nonpartisanship, bipartisanship, judicial independence, and constitutional monarchy.

Professionalism as a political strategy would seem to have the least chance of success in two closely related kinds of environment: 1) the environment of totalitarianism and 2) the environment of a political system with severe ideological fragmentation. In neither of these environments is the claim of expert neutrality likely to be validated (Fried, 1969:159).

The best-intentioned and most skillful planners can and will find the age-old verities of apathy and alienation to be particularly confounding (Brager, 1963:34-40). This may hold true particularly for the "normally powerless, unaffiliated groups" (Burke, 1967:254). W'nen Helen Harris Perlman (1965:413-414) wrote, very eloquently, that "self-determination . . . is the very essence of mature humanness . . . " it can be stated without any adulteration that the actual reality of ascertaining the prompt implementation of this noble and lofty concept with the powerless, the unaffiliated on a planning basis is a most Herculean chore indeed. But the planner must attempt to perceive those values held by the ones most hidden from view, as well as the values of the omnipresent elite, and all in between. Ultimately, all values are of inestimable notability in any efficacious planning process. 


\section{References}

Altshuler, Alan

1965 "The goals of comprehensive planning." Journal of the American Institute of Planners 31 (Aug.).

Adrian, Charles

1960 "The community setting." Social Science and Community Action (East Lansing: Michigan State University Press).

Bergson, Henri

1939 Creative Evolution. New York: Holt, Rinehart and Winston.

Biestek, Flex P.

1957 The Casework Relationship. Chicago: Loyola University Press.

Brager, Geroge

1963 "Organizing the unaffiliated in low-income areas." Social Work 8 (April).

Burke, Edmund $M$.

1965 "The road to planning: An organizational analysis." Social Service Review 39 (Sept.).

1967 "The search for authority in planning." Social Service Review 41 (Sept.).

Carzo, Rocco Jr. and John N. Yanouzas

1967 Formal Organization: A Systems Approach. Homewood, III.: Irwin \& Dorsey.

de Chardin, Pierre Teilhard

1961 The Hymn of the Universe. New York: Harper \& Row.

Coughlin, Bernard

1961 "Community planning: A challenge to social work." Social Work 6 (Oct.).

Cranston, Maurice

1969 "Herbert Marcuse." Encounter 32 (March).

Davenhaver, Bernard $P$.

1971 "Value and artistic value in Le Senne's philosophy." Tulane Studies in Philosophy 20.

Davidoff, Paul

1965 "Advocacy and pluralism in planning." Journal of the American Institute of Planners 31 (Nov.).

Davidoff, Paul and Thomas A. Reiner

1962 "A choice theory of planning." Journal of the American Institute of Planners 28 (May). 
Emmet, Dorothy

1967 "Ethics and the social worker." In Eileen Younghusband (comp.), Social Work and Social Values. London: Allen and Unwin, Ltd.

Erikson, Erik

1960 "Youth and the life cycle." Children 7 (March - April).

Firey, Walter

1965 Law and Economy in Planning. Austin, Texas: University of Texas Press.

Fisher, Jack C.

1962 "Planning the city of socialist man." Journal of the American Institute of Planners 28 (Nov.).

Frankena, William K.

1967 "Value and valuation." Encyclopedia of Philosophy 8. New York: Macmillan Company and The Free Press.

Fried, Robert C.

1969 "Professionalism and politics in Roman planning." Journal of the American Institute of Planners 35 (May).

Friedrichs, Robert W.

1970 A Sociology of Sociology. New York: The Free Press.

1972 "Impact of social and existential factors on scientific judgment." Lecture given at Tulane University, Nov. 2.

Ginsburg, Saul

1950 "Value and the psychiatrist." American Journal of Orthopsychiatry 20 (July).

Gouldner, Alvin

1968 "The sociologist as partisan: Sociology and the welfare state." The American Sociologist 3 (May).

Howard, Donald S.

1969 Social Welfare: Values, Means, and Ends. New York: Random House.

Kahn, Alfred J.

1969 Theory and Practice of Social Planning. New York: Russell Sage Foundation.

Kaitz, Edward M. and H. H. Hyman

1970 Urban Planning for Social Welfare. New York: Praeger.

Kelson, Hans

1957 What Is Justice? Berkeley and Los Angeles: University of California Press. 
Kluckhohn, Clyde et. al.

1971 "Values and value-orientations in the theory of action." In Talcott Parsons and Edward A. Shils, Toward a General Theory of Action. Cambridge: Harvard University Press.

Laing, R. D.

1965 The Divided Self. Baltimore: Penguin Books.

Lappin, Ben

1967 "Commentary." In Integration of Physical and Social Planning. Parkdale, Ottawa: The Canadian Welfare Council.

Litwak, Eugene and Lydia Hylton

1962 "Interorganizational analysis: A hypothesis on co-ordinating agencies." Administrative Science Quarterly 6 (March).

Maas, Henry

1958 "Social casework." In Walter Friedlander (ed.), Concepts and Methods of Social Work. Englewood Cliffs: Prentice-Hall.

Maclver, R. M.

1965 "The responsibility is ours." In R. M. Maclver (ed.), Assualt on Poverty. New York: Harper and Row.

Plant, Raymond

1970 Social and Moral Theory in Casework. London: Routledge and Kegan Paul, Ltd.

Manser, Gordon

1960 "A Critical look at community planning." Social Work 5 (April).

Marris, Peter

1962 "The social implications of urban redevelopment." Journal of the American Institute of Planners 28 (Aug.).

May, Rollo

1967 Man's Search for Himself. New York: Signet.

Mayo, Leonard W.

1941 "Councils in social work." A Social Work Year Book. New York: Russell Sage Foundation.

Mencher, Samuel

1964 "Current priority-planning." Social Work 9 (July).

Morris, Robert

1966 "Social planning." Henry S. Maas (ed.), Five Fields of Social Service. 
1969 "Strategies for innovation in service delivery." In Williard C. Richan (ed.), Human Services and Social Work Responsibility. New York: National Association of Social Workers.

Morris, Robert and Robert H. Binstock

1966 Feasible Planning for Social Change. New York: Columbia University Press.

Mrydal, Gunnar

1958 Value in Social Theory. London: Routledge and Kegan Paul, Ltd.

Newman, John Henry Cardinal

1959 The Idea of a University. Garden City, New York: Image Books.

O'Neill, John

1972 "Can phenomenology be critical?" Philosophy of the Social Sciences 2 (March).

Parson, Talcott

1951 The Social System. New York: The Free Press of Glencoe, Inc.

Pascal, Blaise

n.d. The Thoughts of Blaise Pascal. Garden City, New York: Dolphin Books.

Peattie, Lisa R.

1968 "Reflections on advocacy planning." Journal of the American Institute of Planners 34 (March).

Perlman, Helen Harris

1965 "Self-determination: Reality or illusion?" The Social Service Review 39 (Dec.).

Pope, Alexander

1950 "An essay on man." In Maynard Mack, The Augustans. Englewood Cliffs: Prentice-Hall, Inc.

Rein, Martin

1968 "The scope and function of social services." Intergration of Physical and Social Planning, Report No. 2, The Canadian Welfare Council. Ottawa, Canada.

1969 "Social planning: The search for legitimacy." Journal of the American Institute of Planners 35 (July).

1970 Social Policy: Issues of Choice and Change. New York: Random House.

Rescher, Nicholas

1967 "Values and the explanation of behaviour." The Philosophical Quarterly 18 (April).

Simey, T. S.

1968 Social Science and Social Purpose. New York: Schocken Books. 


\section{Toffler, Alvin}

1972 Future Shock. New York: Random House.

Williams, R. M.

1965 American Society. New York: Alfred A. Knopf. 